\title{
An NMR Study of a Poly(glutamic acid) Metal Complex
}

\author{
Osamu Iwaki, Kunio Hikichi, and Motozo Kaneko \\ Department of Polymer Science, Faculty of Science, \\ Hokkaido University, Sapporo, Japan.
}

Shozo Shimizu and Tetsuo Maruyama

Japan Electron Optics Laboratory Company, Akishima, Tokyo, Japan.

(Received October 13, 1972)

\begin{abstract}
The interactions of poly(glutamic acid) with cobaltous ions (Co(II)) in aqueous solution were investigated by means of NMR in the temperature range from 0 to $70^{\circ} \mathrm{C}$. It was found that as $\mathrm{Co}(\mathrm{II})$ is added the $\alpha-\mathrm{CH}$ and the $\mathrm{NH}$ peaks shift to higher fields and the $\beta-\mathrm{CH}_{2}$ and $\gamma-\mathrm{CH}_{2}$ peaks shift to lower fields. It is considered that these shifts are paramagnetic shifts due to the paramagnetism of $\mathrm{Co}(\mathrm{II})$. Large shifts of the $\gamma-\mathrm{CH}_{2}$ peak indicate that $\mathrm{Co}$ (II) is coordinated with the carboxyl group. High-field shifts of the peak suggest that $\mathrm{Co}(\mathrm{II})$ is coordinated with the peptide NH. Paramagnetic shifts of the $\beta-\mathrm{CH}_{2}$ and $\gamma-\mathrm{CH}_{2}$ increased and those of the $\alpha-\mathrm{CH}$ and $\mathrm{NH}$ decreased with increasing temperature. These results are interpreted in terms of changes in a chemical equilibrium between the Co(II)-free residues of PGA and the bonding ones. It is considered that the amount of $\mathrm{Co}(\mathrm{II})$ bonded to the carboxyl groups of PGA increases with increasing temperature. The temperature dependence of the shifts of $\beta-\mathrm{CH}_{2}$ and $\gamma-\mathrm{CH}_{2}$ suggests that the pseudocontact mechanism is also involved as well as the contact one.
\end{abstract}

KEY WORDS Nuclear Magnetic Resonance / Poly(glutamic acid) / Cobaltous Ion / Paramagnetic Shift /

So far the interactions of poly(glutamic acid) (PGA) with metal ions have been studied by various methods, such as potentiometric, spectroscopic and optical rotatory dispersion measurements. $^{1,2}$ Most of these investigations are concerned with changes in physicochemical properties accompanied with the helix-coil transition. On the basis of ESR measurements, Yamazaki, et al. ${ }^{3}$ reported that $\mathrm{Cu}(\mathrm{II})$ is bonded not only with the carboxyl group, but also with the peptide NH. Except for these reports, there have been few reports on the interaction between PGA and transition metal ions in aqueous solution.

The purpose of this study is to use nuclear magnetic resonance (NMR) spectroscopy to clarify the mechanism of the interaction between PGA and $\mathrm{Co}(\mathrm{II})$. It is known that $\mathrm{Co}(\mathrm{II})$ has a short electron relaxation time, ${ }^{4-6}$ so that, in spite of the paramagnetism of $\mathrm{Co}(\mathrm{II})$, proton NMR spectra of solutions containing $\mathrm{Co}(\mathrm{II})$ are not broad compared to those of solutions containing other transition metal ions, such as $\mathrm{Cu}$ (II) and $\mathrm{Mn}(\mathrm{II})$. Luz and Meiboom ${ }^{5}$ observed NMR spectra of methanolic solutions of $\mathrm{Co}$ (II) and $\mathrm{Ni}$ (II) over a wide temperature range and they estimated the exchange rate of the methanol coordinated to $\mathrm{Co}(\mathrm{II})$ and $\mathrm{Ni}(\mathrm{II})$. McDonald and Phillips ${ }^{6}$ showed the proton signals of an aqueous solution of histidine is shifted by the presence of $\mathrm{Co}(\mathrm{II})$. They proposed possible structures for a histidine-Co(II) complex.

In this report, we present results of studies on the $\mathrm{Co}(\mathrm{II})$ induced shifts in the NMR spectra of PGA.

\section{EXPERIMENTAL}

A sample of the sodium salt of poly(Dglutamic acid) (NaPDGA) was kindly offered by Ajinomoto Co., Ltd. The molecular weight of this NaPDGA was about 80000 . Any trace of 
impurity was not detected in the NMR spectra. $\mathrm{CoCl}_{2} \cdot 6 \mathrm{H}_{2} \mathrm{O}, \mathrm{NiCl}_{2} \cdot 6 \mathrm{H}_{2} \mathrm{O}, \mathrm{MgCl}_{2} \cdot 6 \mathrm{H}_{2} \mathrm{O}$, and $\mathrm{BaCl}_{2} \cdot 6 \mathrm{H}_{2} \mathrm{O}$ were purchased from Koso Chemical Co. and used without further purification.

NaPDGA was dissolved in $\mathrm{D}_{2} \mathrm{O}$ to give concentrations of 2,4 and $6 \mathrm{~g} / 100 \mathrm{cc}$. The $\mathrm{Co}$ (II) solutions were made by dissolving $\mathrm{CoCl}_{2} \cdot 6 \mathrm{H}_{2} \mathrm{O}$ into $\mathrm{D}_{2} \mathrm{O}$. The molar mixing ratio, $R$, of cobaltous ion to a glutamic acid residue was varied from 0 to 0.23 , by varying the $\mathrm{Co}(\mathrm{II})$ concentration and keeping the polymer concentration constant.

The NMR spectrometer used was a JNM-C$60 \mathrm{HL}$ (JEO1. Co.). A $100-\mathrm{MHz}$ spectrometer (JNM-4H-100) was also used, if needed. Both instruments were equipped with variable temperature probes. The sample temperature was varied between 0 and $70^{\circ} \mathrm{C}$. Spectra were observed in the mode of NMR controlled field sweep. A few drops of $t$-butanol were added to each solution, and its methyl resonance line was taken as an internal reference standard. All values for chemical shifts are given in ppm from this signal and down field shifts are assigned positive values.

\section{RESULTS AND DISCUSSION}

The $60-\mathrm{MHz}$ proton NMR spectrum of $2-\%$ NaPDGA in $\mathrm{D}_{2} \mathrm{O}$ solution at $28^{\circ} \mathrm{C}$ is presented in Figure 1. Peak $\mathrm{E}$ is the signal of $t$-butanol. Peak B, appearing at $c a$. $1 \mathrm{ppm}$, is asymmetric in shape and in the $100-\mathrm{MHz}$ spectrum was found to be separated into two lines, a broader one, $\mathbf{B}_{1}$, at higher field and a sharper one, $\mathbf{B}_{2}$, at lower field. When $\mathrm{H}_{2} \mathrm{O}$ was used as the solvent, a signal $\mathrm{D}$ appeared at $c a .7 .3 \mathrm{ppm}$.

On the basis of the NMR spectra of glutamic acid monomer, ${ }^{7}$ and poly $(\gamma$-benzyl-L-glutamate $),{ }^{8}$ we assigned the peaks $A, B_{1}, B_{2}, C$, and $D$ to $\alpha-\mathrm{CH}, \quad \beta-\mathrm{CH}_{2}, \gamma-\mathrm{CH}_{2}, \mathrm{HDO}$, and peptide $\mathrm{NH}$ protons, respectively. When $\mathrm{D}_{2} \mathrm{O}$ was used as the solvent, the peptide $\mathrm{NH}$ proton signal could not be observed. This is thought to be due to the exchange between the $\mathrm{NH}$ proton and the deuterium of $\mathrm{D}_{2} \mathrm{O}$.

It was found that, as $\mathrm{Co}$ (II) was added, the $\alpha-\mathrm{CH}$ and the $\mathrm{NH}$ peaks shifted to higher fields, whereas the $\beta-\mathrm{CH}_{2}$ and the $\gamma-\mathrm{CH}_{2}$ peaks shifted to lower fields. At high $\mathrm{Co}(\mathrm{II})$ concentrations, the $\gamma-\mathrm{CH}_{2}$ peak was separated into two lines. The spectrum of 2-\% NaPDGA solution containing $\mathrm{Co}(\mathrm{II}) \quad(R=0.18)$ observed at $28^{\circ} \mathrm{C}$ is shown in Figure 2. In Figure 3, the shifts of the $\alpha-\mathrm{CH}, \beta-\mathrm{CH}_{2}, \gamma-\mathrm{CH}_{2}$, and $\mathrm{NH}$ lines are shown against the $\mathrm{Co}(\mathrm{II})$ concentration.

The shifts observed in the present work are more than $1 \mathrm{ppm}$, and are greater than that

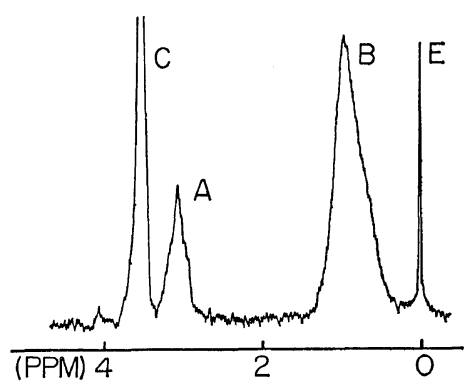

Figure 1. The $60-\mathrm{MHz}$ proton NMR spectrum of 2-\% NaPDGA in $\mathrm{D}_{2} \mathrm{O}$ solution at $28^{\circ} \mathrm{C}$.

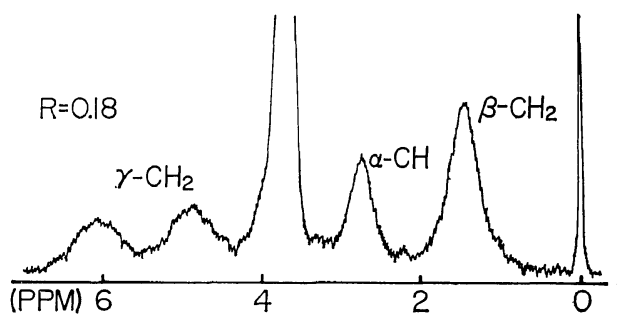

Figure 2. The $60-\mathrm{MHz}$ proton NMR spectrum of 2-\% NaPDGA in $\mathrm{D}_{2} \mathrm{O}$ solution containing $\mathrm{Co}(\mathrm{II})$ $(R=0.18)$ at $28^{\circ} \mathrm{C}$.

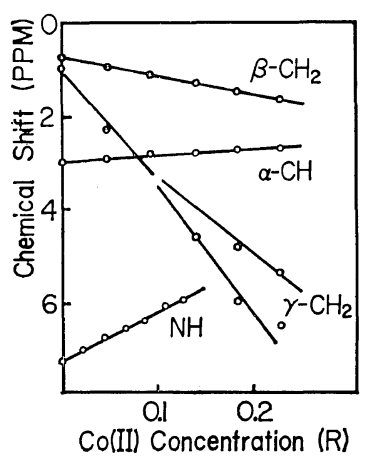

Figure 3. The shifts of $\alpha-\mathrm{CH}, \beta-\mathrm{CH}_{2}, \gamma-\mathrm{CH}_{2}$ and $\mathrm{NH}$ peaks vs. the ratio of the number of $\mathrm{Co}(\mathrm{II})$ ions to the number of glutamic acid residues, $R$. Data for NH were obtained at $24^{\circ} \mathrm{C}$ and other data at $28^{\circ} \mathrm{C}$. 
observed in the course of the helix-coil transition. $^{9}$ It cannot be considered that the shifts are due to the helix-coil transition, which might be induced by adding the salt. It is reported that such large shifts could arise from an electrostatic effect or from the paramagnetism of $\mathrm{Co}(\mathrm{II}){ }^{10}$

In order to estimate the contributions to the shifts from the electrostatic effects, we examined the NMR spectra of NaPDGA for the effects of divalent salts such as $\mathrm{CaCl}_{2}, \mathrm{MaCl}_{2}$, and $\mathrm{BaCl}_{2}$. The shifts induced by those ions are very small compared to those of $\mathrm{Co}(\mathrm{II})$. This fact indicates that the shifts induced by $\mathrm{Co}$ (II) are not due to the electrostatic effect, but the paramagnetism of $\mathrm{Co}(\mathrm{II})$.

There are two mechanisms for the paramagnetic shift, one is the contact shift and the other the pseudocontact shift. The contact shift is observed when an unpaired electron-spin density is finite at the resonance nucleus. ${ }^{11}$ The pseudocontact shift is observed in complexes when a paramagnetic ion has an anisotropic $g$ factor and occupies a particular position relative to the ligand molecule. ${ }^{12}$ In general, $\mathrm{Co}(\mathrm{II})$ is known to have an anisotropic $g$ factor. ${ }^{13}$

PGA has the carboxyl group $\mathrm{COOH}$, the peptide $\mathrm{NH}$ and $\mathrm{CO}$ each of which is able to form a coordinate bond to $\mathrm{Co}(\mathrm{II})$. Large shifts of the $\gamma-\mathrm{CH}_{2}$ and $\mathrm{NH}$ lines indicate that the $\mathrm{Co}(\mathrm{II})$ is coordinated with the $\gamma$-carboxyl and $\mathrm{NH}$ groups. In fact, it is reported that the protons bonding to nitrogen atoms show up-field shifts when the nitrogen atoms coordinate to $\mathrm{Co}(\mathrm{II})^{4}$. The fact that the $\beta-\mathrm{CH}_{2}$ paramagnetic shifts are smaller than those of the $\gamma-\mathrm{CH}_{2}$ is interpreted as follows. When a coordinate bond between $\mathrm{Co}$ (II) and the carboxyl group is formed, a little of the unpaired electron-spin density will be transmitted from the carboxyl group to the $\gamma$ - and $\beta$-carbons of PGA. It is rapidly attenuated with going from the $\gamma$-carbon to the $\beta$-carbon. Therefore, the smaller unpaired electron density of the $\beta-\mathrm{CH}_{2}$ results in a smaller paramagnetic shift for the $\beta-\mathrm{CH}_{2}$.

Both areas under the two lines of the $\gamma-\mathrm{CH}_{2}$ are equal to each other at all concentrations of $\mathrm{Co}(\mathrm{II})$. This indicates that the two lines are due to the respective protons of the $\gamma-\mathrm{CH}_{2}$. The difference in shifts of the two protons of
$\gamma-\mathrm{CH}_{2}$ shows a different magnetic environment at each proton, which is considered to be due to the particular orientation of the side chain of the PGA relative to the $\mathrm{Co}(\mathrm{II})$. The particular orientation of the side chain may be caused by a chelate ring, formed by the coordination of the $\gamma$-carboxyl and peptide NH. A similar result is reported for the lines of $\alpha-\mathrm{CH}_{2}$ in the spectrum of the $\mathrm{N}$-methyl glycine-Ni(II) complex. ${ }^{4}$ The line of $\alpha-\mathrm{CH}_{2}$ splits into two lines, when a 5-membered ring is formed in the $N$ methylglycine complex with $\mathrm{Ni}(\mathrm{II})$.

Spectra of PGA solutions containing $\mathrm{Co}(\mathrm{II})$ were obtained from 0 to $70^{\circ} \mathrm{C}$. It was found that with increasing temperature the paramagnetic shifts of $\beta-\mathrm{CH}_{2}$ and $\gamma-\mathrm{CH}_{2}$ increased while those of $\mathrm{NH}$ and $\alpha-\mathrm{CH}$ decreased. In Figure 4 , the paramagnetic shifts measured from the values of chemical shifts in the absence of $\mathrm{Co}$ (II) are plotted against the reciprocal temperature. In general, paramagnetic shifts are reported to be proportional to the reciprocal temperature. ${ }^{11,12}$ The present results do not obey this rule. These results can be interpreted in terms of the change in a chemical equilibrium between the $\mathrm{Co}(\mathrm{II})$ free residues of PGA and $\mathrm{Co}(\mathrm{II})$-bonding ones. If a fast exchange between two species occurs, the position of the observed line is a weighted averag of the two lines from the respective species. It is, therefore, expected that the observed shift varies if the relative concentration of the two species varies with temperature. The

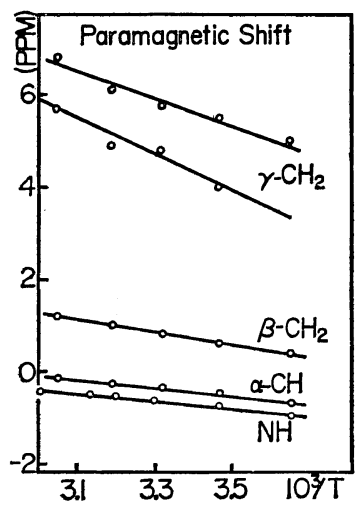

Figure 4. $\mathrm{Co}(\mathrm{II})$-induced paramagnetic shifts as a function of the reciprocal temperature for 4-\% NaPDGA solutions containing $\mathrm{Co}$ (II) $(R=0.06$ for $\mathrm{NH}$ and $R=0.23$ for others). 
increase of the observed paramagnetic shifts of $\beta-\mathrm{CH}_{2}$ and $\gamma-\mathrm{CH}_{2}$ indicates an increase of the $\mathrm{Co}$ (II)-bonded carboxyl groups of PGA with increasing temperature.

The ratio of the observed paramagnetic shift of the $\beta-\mathrm{CH}_{2}$ relative to that of the $\gamma-\mathrm{CH}_{2}$ depends on temperature. If the shift is caused by the contact mechanism alone, the ratio will be independent of temperature, because the ratio is related simply to the hyperfine constant which is not considered to depend on temperature. On the other hand, if the shift is caused by the pseudocontact mechanism, the ratio may depend on temperature, since the ratio is related to the position of the metal ion relative to the protons of $\beta-\mathrm{CH}_{2}$ and $\gamma-\mathrm{CH}_{2}$, and this relative position may be varied with thermal motion.

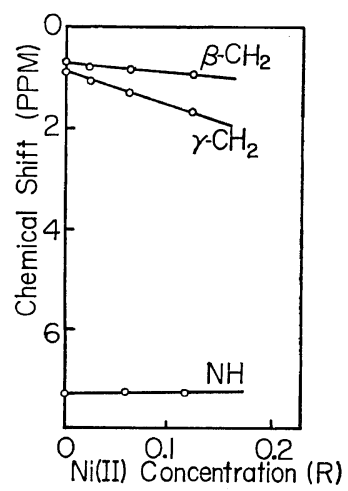

Figure 5. The shifts of $\beta-\mathrm{CH}_{2}, \gamma-\mathrm{CH}_{2}$, and NH peaks $v s$. the ratio of the number of $\mathrm{Ni}(\mathrm{II})$ ions to the number of glutamic-acid residues, $R$. Data for $\mathrm{NH}$ were obtained at $36^{\circ} \mathrm{C}$ and other data at $28^{\circ} \mathrm{C}$.

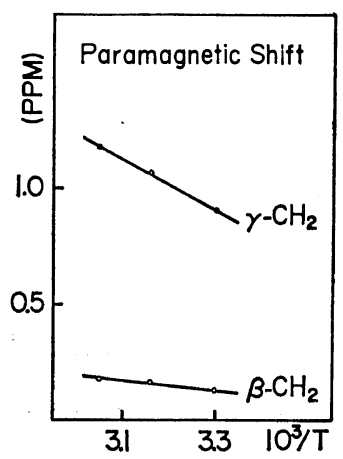

Figure 6. $\mathrm{Ni}(\mathrm{II})$ induced paramagnetic shifts as a function of reciprocal temperature for $4-\%$ NaPDGA solutions containing $\mathrm{Ni}(\mathrm{II})(R=0.13)$.
$\mathrm{Ni}(\mathrm{II})$ is known to have an isotropic $g$ factor in aqueous solution, ${ }^{14}$ therefore, there is no contribution from pseudocontact shift. In order to clarify that the ratio in the case of contact mechanism is independent of temperature, the effect of $\mathrm{Ni}(\mathrm{II})$ upon the NMR spectra of PGA was examined with the same procedures as for $\mathrm{Co}(\mathrm{II})$. When $\mathrm{Ni}(\mathrm{II})$ was added to NaPDGA solutions, peaks of $\beta-\mathrm{CH}_{2}$ and $\gamma-\mathrm{CH}_{2}$ were found to shift to lower fields in the same way as those of $\mathrm{Co}(\mathrm{II})$. The peak of the $\alpha-\mathrm{CH}$ was screened with HDO signal. In Figure 6, the paramagnetic shifts measured from the values of chemical shifts in the absence of $\mathrm{Ni}(\mathrm{II})$ are plotted against the reciprocal temperatures. The result shows that the ratio of the paramagnetic shifts of the $\beta-\mathrm{CH}_{2}$ relative to that of the $\gamma-\mathrm{CH}_{2}$ is independent of temperature. This fact supports the interpretation that the temperature dependence of the ratio in the case of $\mathrm{Co}$ (II) is due to the pseudocontact mechanism.

It may be concluded that $\mathrm{Co}$ (II) is coordinated with the carboxyl group and the peptide $\mathrm{NH}$, and that a chelate ring is formed. The observed shifts are due to both contact and pseudocontact mechanisms. The amount of $\mathrm{Co}(\mathrm{II})$ bonded to the carboxyl group of PGA increases with increasing temperature.

Acknowledgment. The authors wish to thank Ajinomoto Co. and Professor J. Noguchi of Hokkaido University for furnishing NaPDGA samples.

\section{REFERENCES}

1. A. L. Jacobson, Biopolymers, 1, 269 (1963).

2. A. L. Jacobson, ibid., 2, 237 (1964).

3. H. Takesada and H. Yamazaki, ibid., 4, 713 (1965).

4. R. S. Milner and L. Pratt, Disc. Faraday Soc., 34, 88 (1962).

5. Z. Luz and S. Meiboom, J. Chem. Phys., 40, 2686 (1964).

6. C. C. McDonald and W. D. Phillips, J. Amer. Chem. Soc., 85, 3736 (1963).

7. Y. Kobayashi and H. Makino, Biochim. Biophys. Acta, 191, 738 (1969).

8. E. M. Bradbury and C. Robinson, Nature, 220, 1079 (1968).

9. J. L. Markly, D. H. Meadows, and O. Jardetzky, J. Mol. Biol., 27, 25 (1967). 
An NMR Study of a Poly(glutamic acid) Metal Complex

10. J. A. Pople, W. G. Schneider, and H. J. Bernstein, "High Resolution Nuclear Magnetic Resonance." McGraw-Hill Book Company, New York, N.Y., 1959, p 449.

11. N. Bloembergen, J. Chem. Phys., 27, 595 (1957).
12. H. M. McConnell and E. Robertson, J. Chem. Phys., 29, 1361 (1958).

13. B. Bleaney and D. J. E. Ingram, Proc. Roy. Soc., 208, 143 (1951).

14. G. N. La Mar, J. Chem. Phys., 41, 2992 (1964). 